\title{
¿EN ESTADO CRÍTICO? \\ SOBRE CIERTAS FORMAS DE ESCRITURA ENSAYÍSTICA ACTUAL Y SOBRE LAS MUTACIONES DE LA CULTURA PENINSULAR CONTEMPORÁNEA QUE LAS HAN HECHO POSIBLES
}

\author{
Germán Labrador Méndez \\ (Princeton University)
}

Estas páginas nacen de una amable invitación. Desde la revista en la que aparecen, me propusieron reflexionar sobre el género ensayístico desde una noción provocadora y abierta: la de la disolución del pensamiento o, directamente, la de su destrucción. Y, en el momento, me pareció una gran idea. Ahora que las he escrito, me doy cuenta de que nada habrá particularmente iconoclasta en ellas, ni en los objetos de los que me ocupo: libros publicados recientemente, en formato papel (y a veces digital), adscritos al territorio de la no ficción, los cuales se relacionan con el dispositivo cultural ensayo de un modo (creo que) interesante. Lo que me planteo aquí es entonces un conjunto de observaciones —no particularmente singulares ni necesariamente sorprendentes - elaboradas a partir de ciertas experiencias de lectura personales y recientes (en algunos casos muy recientes) a partir de materiales que, de una u otra forma, caen en el género ensayo. $\mathrm{Si}$, en cierto modo, ningún género literario existe fuera de sus manifestaciones concretas, esa afirmación es aún más concreta a propósito del ensayismo, entendido como una escritura cuyo motivo explícito es la discusión, reflexión o elaboración conceptual. Si el género se manifiesta en su performatividad, como nos explicó Judith Butler, ello es cierto también para los géneros del escribir y del leer. Así, aunque toda prosa es prosa de ideas, hay zonas de escritura que se articulan explícitamente desde un régimen no ficcional. Desde allí, nos sentimos 
cómodas al ensayar una definición de ensayo (me apresuro a advertir que este texto quiere decirse en plural femenino inclusivo: así comenzamos a ensayar género y generar ensayo).

No hay género sin su puesta en escena, ni escritura en abstracto sin su materialización, por lo que me propongo interrogarme por las derivas últimas de las formas de escritura ensayísticas de un aquí y ahora ibérico desde experiencias singulares. Hablo de una pequeña colección de libros de ensayo, libros de los que me he ocupado últimamente. Como detrás de toda reflexión estética hay (implícitos) prototipos, modelos y ejemplos que validan especialmente (o no) una determinada consideración, prefiero hacerlo al revés, comenzando desde lo concreto, desde la contingencia de una limitada selección de textos ensayísticos que me ha interesado en los últimos meses, y declarando que estoy pensando desde ellos. Solo en un segundo momento, al preguntarme por las razones de mi interés, he comenzado a preguntarme cómo fueron compuestos, en qué tensiones, por medio de qué procedimientos, mediante qué diálogos con qué dispositivos y audiencias. La singularidad de algunos de estos ensayos me ha parecido sugerente y ha alimentado algunas reflexiones posteriores que aquí compartiré. El texto tiene así dos partes: en la primera, presento un puñado de textos ensayísticos, en la segunda trato de pensar sobre lo que mi interés por los mismos puede manifestar de modo más general y paradigmático.

Insisto: hay muy poco de iconoclastia en las páginas que siguen. El pensamiento no se crea ni se destruye, sino que se con-forma, porque existe mediante tomas de lenguaje concretas, por medio de formas de habla y de escritura a su vez móviles, circulantes. Y así, cuando me puse a pensar en la «destrucción del ensayo», tuve que contenerme. Me acordé de incumplidas proclamas apocalípticas de no hace tanto. Recordé otros fines y finales de otras formas literarias y de los agentes culturales que las ejecutaban. Fines de la historia y de la novela, de la utopía o del compromiso, del libro en papel o — directamente- de la cultura occidental ha habido muchos. Y cuántas veces el deseo de un fin enmascara el temor al fin propio, cuántas veces el final de un mundo quiere conjurar el propio final. Si, como diseccionó lúcidamente Jordi Gracia en tiempos quincemayistas, hay melancolías y ansiedades propias del fin de un tipo concreto de intelectual que no dudan en enunciarse como «el fin del intelectual» a secas y es conveniente evitarlas, huirlas como a la peste, yo también quiero escaparme lejos, huir de cualquier posible "destrucción del pensamiento», para ensayar un pensamiento que todavía 
pueda construir mundo común. Por eso, más que del biblioclasmo, hablaré de su metamorfosis: la percepción terminal de una determinada forma de escritura socialmente reconocible puede solaparse con los efectos de su mutación, de su expansión, de su desbordamiento. Hay pocas fantasías más gratas al ejercicio privilegiado del saber que la especulación con su disolución, con su muerte. Como cantaría Lesley Gore (It's my party and I cry if I want to), la retórica apocalíptica representa el privilegio en el mismo ejercicio de negarlo (y de negárselo a otras). No puede ser esa mi entrada. Quienes queremos que el mundo sea más hermoso y más bueno no nos resignaremos fácilmente a su desaparición. $\mathrm{Ni}$ a la de los ámbitos donde así lo convocamos. Habrá que ensayar otra cosa.

No hay forma de destruir el pensamiento. Pero puede pensarse de otras formas $-\mathrm{y}$ en otras formas, a través de ellas-. Ignoro qué le pasa hoy —aquí y ahora-al ensayo y la escritura de ideas, ese territorio de tomas de palabras y publicaciones del que esta revista habla. No se me da bien hablar así, en general, prescindiendo de lo concreto, de lo único que en realidad existe. Pero puedo decir, sin embargo, que sí me parece percibir en algunos ensayos — los que estoy leyendo, los que me interesan - fenómenos curiosos que apuntan no hacia la destrucción de un género, pero sí a su desbordamiento, a la expansión de una cierta escritura en relación con los espacios donde esta solía darse y en relación con las tecnologías que la vehiculaban, con sus públicos y con su modo de producción. Restringiéndome al análisis más concreto, en algunos de estos ensayos parecería que ciertas pautas que tendían a identificar el género están en transformación. Sin ningún afán taxonómico, hablaré de un cierto, relativo ensayo de expansión de la escritura, que supone permitir otras formas de afectación de lo social y, al tiempo, albergar sus afecciones y afectos. Me apresuro a declarar que no hay nada intrínsecamente nuevo en los fenómenos a los que aquí atenderé, pero no por ello resultan menos interesantes. Reconozco también que mi selección de textos —ocho libros recientes - es arbitraria y, sin embargo, creo que sí es posible arbitrar algo a partir de la misma, pues, al cabo, la pregunta por el arbitrio es la pregunta por aquello a lo que damos valor.

Por mi propia forma de trabajar, en la encrucijada entre la filología, la historia cultural, los estudios culturales y sus disciplinas aliadas, en un marco conceptual que he descrito en otra parte (Labrador Méndez 2016) asumo que los libros leen y son leídos por dentro, pero también alrededor. Los libros son y devienen mundo desde prácticas diversas y complejas que no se 
ejercen únicamente dentro de su superficie textual, desde sus contenidos y estilos. Ello importa para atender también a la construcción y circulación de formas: de los ensayos que aquí analizo me interesa saber no sólo lo que dicen y la manera de decirlo, sino también cómo están hechos y quiénes los han hecho, y cómo son enunciados, circulados o discutidos. Ojalá estas preguntas trabajen en favor de una topografía más compleja (y quizá menos visible) de algunas tomas de escritura propias del género actualmente, pero antes de comenzar este trabajo cabe realizar una precisión más: el carácter reciente de mis ejemplos impide conocer sus efectos y respuestas en un plazo de tiempo razonable. En todo caso, en ellos, y en su circulación, se anuncian síntomas que ya, desde ahora, me interesan. Hay diversidad en los casos, en la tipología de sus autoras, en sus dispositivos. Los ocho textos seleccionados están ordenados por riguroso orden de lectura. Al primero - por su singularidad - le dedico una mayor atención mientras que, en los demás, procedo de forma más escueta, dirigiéndome específicamente a los síntomas centrales de los mismos en relación con los argumentos que desplegaré en la última parte de mi artículo.

\section{Una operación singular: hacia un ensayo de una España vacía.}

El primero de los ocho ensayos se ha convertido en un best-seller. Ha pasado a leerse en los aeropuertos y trenes de alta velocidad que cruzan ese país mal estructurado y vacío del que habla Sergio del Molino en La España vacía (2016), libro donde se discuten y revisan los imaginarios de la españolitud (Izquierdo 2014) desde la articulación simbólica y material de los espacios interiores del estado. Para ello, resulta preciso hacerse cargo de la despoblación y destrucción de los mundos rurales de la meseta. Poco queda de ello después del éxodo brutal de la posguerra — que del Molino llama «el gran Trauma»— más que la memoria cultural de su riqueza imaginaria, del tesoro de mitos, literatura, imágenes que los habita y configura históricamente. La España de Las Hurdes y El Quijote, de las leyendas de Bécquer y el Carlismo flota sobre las violencias del éxodo urbano posterior a la Guerra Civil. Sobre estos cortes de memoria e identidad la democracia acelera hoy estas rupturas, al servicio de una modernidad neoliberal. Del Molino elabora históricamente la dimensión simbólica del paisaje devastado de la nación, desvelado durante la crisis (López y Rodríguez 2010). En lo genérico, La España vacía es un ensayo de manual, que combina literatura y crónica, observación y documentación, gracias a un estilo ameno y metafórico. Un mérito adicional reside en su capacidad de dialogar 
y disputar —un siglo después, cuando pocas lo consideran útil— el canon del casticismo, replicando — consciente y metaliterariamente- el gesto noventayochista de preguntarse por la meseta y por sus paisajes, por sus vidas y por sus muertes, aquel espejo formidable de decadencias y regeneraciones que el estado usó para imaginarse castellanamente durante siglo y medio. Al autor, anteriormente novelista de dramas interiores, el libro le ha servido para dar un salto notable, creándose un perfil de divulgador y comentarista, un casi coacher en eventos culturales de diversa marca a los que acude armado con un tenedor con punta que debería llamarse forca si hubiera una correcta relación con el campo. Su presencia digital es otro elemento decisivo de su exitosa gestión como ensayista de moda.

Desde la perspectiva metodológica el libro se declara construido desde «el método literario», aunque desde muy pronto se reconozca el trabajo realizado mediante las herramientas propias de la hermenéutica cultural (nation-making, memoria y monumentalidad, territorialización y visualidad, etc.), convocadas con elegancia (a veces también con superficialidad) para no academizar demasiado la escritura del libro. Pero hay algo que me interesa aún más que las capacidades interpretativas del autor: la inteligente puesta en valor (incluso, la capitalización) de una experiencia laboral y de escritura complicada, la de un periodista de un diario regional, en este caso el Heraldo de Aragón, quien (en una época justo anterior a la actual crisis de los diarios en papel) se veía cotidianamente condenado a largas excursiones por las geografías despobladas de la España de interior. A lo largo del libro, esta experiencia se convoca una y otra vez, como germen de muchos de sus capítulos, haciendo que la experiencia laboral del periodista regional devenga — por medio de la reflexividad del género— análisis colectivo y universalizable. Esa operación, en apariencia anacrónica, propia de otros escritores de la tradición íbera (de Bécquer a Azorín, de Cervantes a Cela), justo de los que Del Molino se ocupa, deviene estrictamente contemporánea cuando el autor se pregunta por las causas históricas y políticas de dicho vaciamiento.

Ninguno de los ensayos que comentaré tiene la relevancia de La España vacía para un número de lectores tan extenso y de tipologías tan variadas. El éxito de la operación en este caso reside en la capacidad del autor de identificar una conversación pendiente —la importancia que tuvo el borrado y desmemoria del éxodo rural y del pasado campesino mesetarioactualizándola a propósito de una cuestiones críticas: la revisión del programa modernizador 
de la España democrática y de sus modelos de desarrollo (y de extracción) en relación con la calamitosa historia de la articulación del territorio-estado español. En esas coordenadas, Del Molino logra nombrar algo pendiente mediante un concepto útil, fácil de recordar y de volver a usar -«la España vacía»- que permite su reapropiación en un contexto de múltiples conversaciones, un poco como sucedió con la noción «C.T.» de Guillem Martínez (2012), aunque sin una carga crítica tan evidente, porque a nadie le puede molestar este libro escrito con sensibilidad y de buen rollo, que evita los muchos campos de berenjenas que también hay en las tierras, las tierras, las tierras de España. En todo caso, cuando en marzo de 2017 uno de los programas de Salvados recibió el titulo de La España vacía y el mismo Follonero entrevistaba a Sergio del Molino, se confirmaba la importancia analítica que había adquirido esta interesante herramienta conceptual. El país estaba hueco.

\section{Siete formas de ensayo concretas publicadas desde 2016.}

El segundo de los textos que aquí convoco me interesa en lo fundamental por sus efectos discursivos, por su capacidad de visibilizar cómo se han expandido los territorios donde la escritura ensayística construye mundo y, en cierto modo, también se han disociado. Se trata del libro de Ignacio Sánchez Cuenca La desfachatez intelectual (2016), del cual, aquí, más que su música, importa el ruido que produjo. Su condición de pimpampum del Parnaso democrático, redujo su recepción a una conversación imposible: de un lado de la trinchera, se censuraban con nombre, ejemplos y apellidos, las faltas de rigor conceptual de una cultura de la opinión logorreica (famosa fue aquella sugerencia filosófica de convertir a los parados en toros de lidia), muy poco acostumbrada a rendir cuentas. Mientras, del otro lado del espejo, se censuró el tono y la supuesta condición «conversa» de su autor, de expulsado de la República literaria por su capacidad o incapacidad de hacer amigos o distintos. Era como si en la recepción del libro se reprodujesen las causas del síntoma que se analizaba. En su circulación polémica se visibilizaba la conciencia de una crisis. La función estructural de los expertos e intérpretes, de todos los ámbitos, estaba en discusión por los efectos epistemológicos derivados de la crisis 2008, y de su respuestas culturales en el 2011. Si, en el contexto del 15M, la democratización radical del pensamiento y de sus escrituras estuvo en el centro de las discusiones, como se ha analizado en detalle (15MP2P 2014), la exploración de las formas y espacios donde este pensamiento se daba 
fue acompañada pronto del cuestionamiento orgánico de los roles de expertos y técnicos, al comprender que tales figuras garantizaban las formas previas de construcción cultural del valor y el orden que se fundaba en ellas (Moreno 2017).

El libro de Sánchez Cuenca flotaba sobre aquellas aguas ciudadanas, aunque tal vez no supo hacerse cargo de la marea de fondo. En todo caso, la fuerza enunciativa de su propuesta no puede comprenderse sino en ese contexto. Desde allí toma conciencia de una crisis de representación cultural, identifica la incapacidad del campo cultural democrático de seguir produciendo autoridad en la esfera pública desde los mismos medios. Desde allí huele los vientos de democratización radical $-y$ desregulación-cultural que el 15M —y la esfera digital desde la que se hace — promueve. Así, con independencia de su opinión del mundo cultural que pone en la picota, las dimensiones del trabajo de Sánchez Cuenca nos hablan de una extensión de la esfera pública sucedida en los últimos años. Basta con comparar las diferentes recepciones que conoció el libro - en la prensa de papel y en los nuevos medios digitales y las redespara percibir la paradoja de una esfera de opinión autorreferencial capaz aún de garantizar sus sentidos internamente, y opaca a las miradas desde afuera. Es una conversación por el momento frustrante, porque no se comparte lenguaje, ni descripción del mundo. En todo caso, la objetivización de los límites socio-ideológicos de las culturas de estado y la construcción de sus afueras ciudadanos y digitales, representa una de las líneas de tensión crítica de los últimos años a propósito de la enunciación del pensamiento crítico.

Mi tercer ejemplo requiere un cambio de foco: se trata del ensayo de Marta Sanz. Éramos mujeres jóvenes. Una educación sentimental de la transición española (Anagrama, 2016), obra de una escritora en estado de gracia, con la máquina de escribir a pleno rendimiento. En general Sanz tiene una escritura autorreflexiva y, por zonas, plenamente ensayística, como manifiesta en su novela Daniela Astor y la Caja Negra (Anagrama, 2013), ya dedicada al mismo periodo y a similar sensibilidad. Son escrituras de memoria histórica, de crítica de los orígenes. Ensayos sobre una transición que, ya a nuestro pesar, o ya con nuestro consentimiento, nos ha vivido, (aun cuando tal vez nosotras no a ella). Desde las efemérides de los cuarenta años de postfranquismo, ha habido muchos ensayos que han sabido cruzar lo personal y lo político en busca de otros linajes para la democracia (Nazario 2016, Sánchez Mateos 2016, Estornés 2017, a su manera Amat 2016 y —ojalá— Labrador 2017b) pero quizá ninguno resulta tan relevante 
como este, por su extraña forma de ubicar su escritura (y su mirada) en el intervalo entre épocas. De entrada, el libro se sitúa en la estela de Vázquez Montalbán (y su educación sentimental bajo el franquismo, 1970), y aún mucho más de Martín Gaite (1978), en la configuración emocional de la generación de Sanz. El libro es la cara B de Daniela Astor y logra introducir, desde nuestro presente, la subjetividad de las madres de Daniela desde la actual perspectiva de Sanz. Permite revisitar la novela desde nuestra necesidad de pensarnos como ciudadanas feministas, usando como puente de ficción histórica, la experiencia real de las mujeres que fueron niñas durante la transición. Para ello, la convocamos desde el lenguaje actual de sus luchas adultas.

Así, desde el ensayo, la memoria y el feminismo, Sanz funda una genealogía democrática desde la experiencia de (mala) educación propia de los años setenta, reservada a quienes doblemente no fueron tenidas en cuenta como sujetos de su época: como niñas y como mujeres de la democracia por venir. Sus desconciertos y las violencias que atraviesan su (ir)representación histórica tienen también que ver con la condición crítica contemporánea de una ciudadanía sin representación, enunciada desde redes y desde plazas. O desde los diversos talleres de lectura en los que actualmente participa Sanz. La escritura ensayística aquí trabaja desde una hibridez que permite coser tiempos y sensibilidades, dar representación y genealogías a sujetos colectivos desde experiencias singulares. Para ello, se combinan tonos sociológicos, la autobiografía y la historia oral, polifonías de vidas propias y ajenas. Para entender mi argumento conviene señalar la inexistencia de equivalentes marcados en masculino que traduzcan esta operación: no puedo identificar un relato histórico colectivo de la transición que implique a una nueva generación y a nuestros lenguajes de protesta donde la experiencia masculina de los niños de la transición sea pertinente, ni siquiera para deconstruir el propio género.

El cuarto de los ensayos que aquí me interesan lo firma Guillem Martínez, bajo el título de La Gran Ilusión. Mito y realidad del proceso indepe (2016), un volumen urgente sobre la coyuntura política desatada alrededor de las actuales reclamaciones catalanas pro-independencia. Martínez interroga el procés con herramientas de análisis discursivo y con ingeniería social propia del periodismo. Es difícil comprender este libro sin el trabajo de años como analista político del propio Martínez primero en directa.cat y luego en ctxt.es, lo que es como decir, sin la emergencia de una nueva prensa crítica en formato digital y, apostados a sus tribunas, de una nueva-vieja generación de periodistas, críticos y escritores. Al tiempo, el paradigma 
hermenéutico de Guillem —y el estilo que lo sostiene - son el resultado decantado de muy largas travesías por el desierto de los dosmiles. Era un tiempo en que el 15M era simplemente impensable pero donde ya existía la expresión «CT» para hablar de las (limitadas) herramientas interpretativas dominantes de la cultura democrática. No era un concepto popular, sino una expresión que sólo remitía al blog del propio Martínez, construida tras años de experiencia en el ecosistema periodístico nacional y ciertas lecturas avanzadas en la carrera filológica. Tal vez no se lo diesen a leer en la Universidad de Salamanca donde estudió, pero Martínez comprende y desmonta la producción de ideología con las herramientas de un Barthes o de un Klemperer. Más allá - también desconozco dónde lo aprendió- en su forma de escribir ensayo hay estilo. Humor, dobles sentidos, ritmo, luces pop y tonos iconoclastas a veces y otras melancólicos. La relativa invisibilidad de este ensayo rotundo en los ámbitos analógicos, hoy contrasta con su profusa recepción digital.

La política en el ocaso de la clase media (2016) es el quinto de los ensayos que aquí considero. Lo firma Emmanuel Rodríguez y es fruto, como sus libros anteriores, de un modo de edición y producción basado en la cultura libre, la circulación digital y las licencias de Creative Commons. Se trata, en fin, del mundo de saberes y de haceres liberados que representan Traficantes de Sueños y sus diversos entornos físicos y digitales aliados, como el Observatorio Metropolitano de Madrid y la Fundación de los Comunes. Son estos mundos decisivos para la conformación de la intellingentsia quincemayista y una de sus raíces históricas. Columnista asiduo de los medios digitales afines a este espacio, Rodríguez es autor o coautor de cinco monografías. Combina —en lo que es un rasgo generacionalmente recurrente- la formación académica especializada y el activismo y la intervención en ámbitos de institucionalidad alternativa (Universidad Nómada, OMM...), mezclando en sus trabajos análisis y opinión y vinculándose de formas muy activas a los procesos políticos de los últimos años. En esta ocasión, Rodríguez hace balance del ciclo 2011-2016, en términos de fin de fiesta, en clave resignada y melancólica, de resolución incompleta de las expectativas transformadoras de su generación, señalando que el supuesto sustrato mesocrático de los valores quincemayistas acabaría actuando como inconsciente colectivo. Se trata de un lugar común en ciertos análisis de actualidad, del $15 \mathrm{M}$ y de sus manifestaciones, que plantean la existencia de una sociología profunda de clase media, que operaría — de modo culpable - bajo un lenguaje de la transformación radical. 
Aunque no se comparta esta lectura, los libros de Rodríguez son ricos inventarios de eventos y de secuencias fundamentales para la interpretación en directo de las transformaciones políticas de los últimos años. Verdaderos ensayos de historia del presente, su propia composición opera también digitalmente, en red y con técnicas de cultura libre. Su capacidad de ver depende de su propia factura. Con otros instrumentos de visión, las partes de la realidad contemporánea que Rodríguez cartografía resultarían invisibles.

El ensayo de Rubén Yuste, Ibex 35. Una historia herética del poder en España (2017) representa el sexto libro que aquí convoco. Fue publicado en Capitán Swing, una de las guaridas del ensayo crítico de nueva generación. El libro de Yuste, en el poco tiempo transcurrido desde la primera escritura de estas páginas, ha adquirido una relevancia imprevista, al convertirse en munición ideológica pesada para la argumentación política de los publicistas y portavoces de Podemos, en su nueva retórica tras Vistalegre 2. Sirvió para actualizar un exitoso concepto anterior, "la casta», la traducción popular de la noción de «élites extractivas», divulgada por Acemoglu y Robinson (2013). La noción de «trama» reforzaba la existencia de grupos sociales parásitos de la estructura pública del estado para enfatizar la interrelación ilícita entre grupos humanos privilegiados y las redes de intereses de las que se sirven. Este relanzamiento de la noción coincidió con la presentación en sociedad del libro de Yuste, que acabaría sirviendo de cimiento ideológico para otras acciones públicas relevantes, como el lanzamiento del famoso «Tramabús». Sin embargo, de este libro me interesaron previamente otras cuestiones: su capacidad de conectar estilo y procesamiento de datos, lo que era coherente con el perfil profesional del propio Yuste, animal híbrido de académico y periodista (hoy, de la necesidad virtud, se habilita como comunicadores públicos a los jóvenes desposeídos de la academia). También me había gustado su estilo como ensayista, con un poderoso comienzo de libro, narrativo, a la manera de Larra: un buen día, por efecto de la escritura, el mundo opaco de la actualidad comenzaba a revelar sus intereses mágicamente ante los ojos de un ciudadano sorprendido. En una suerte de momento Diablo Cojuelo del neoliberalismo, el protagonista-autor del ensayo comenzaba a percibir detrás de la mascarada mediática las tramas corruptas, las deudas y las propiedad de un mundo compartimentado y violento.

El penúltimo de los ensayos que aquí me apelan fue el de Marina Garcés, Fuera de clase (2016), en apariencia una colección de textos — píldoras de realidad— ensayísticos, entre 
lo filosófico y lo periodístico, con múltiples registros: la crónica, la autobiografía, la reflexión intelectual, la bitácora de lecturas, la memoria o la glosa. En su misma materialidad manifiestan la condición duplicada que la autora reivindica: filósofa titular de la Universidad de Zaragoza, activista de mundos en común, Espais en Blanc y Pressentiments. Los mundos de Garcés son duales: trabajadora pública y agente de las redes asociativas de la Barcelona pre y post$15 \mathrm{M}$, viajera entre ciudades y lenguas. Así, los textos de Fuera de clase primero se publicaron en catalán, como recopilación pero, aún antes, como parte de un ejercicio — de estilo y de constancia- de columnismo para el suplemento dominical del diario Ara. Aunque el devenir libro de un puñado de tribunas de prensa es un ejercicio arriesgado, en este caso ha servido para proporcionar a estas escrituras de Garcés otro tiempo, otra vida y otros públicos, que desborden el ámbito catalán y la contingencia dominguera. Así compilados parecen haber sido escritos para gozar de una vida diferente, más duradera, con otros tiempos de pensamiento y lectura. Como cualquier texto, refleja y debe mundo, pero - a diferencia de otros textos- los saberes que estos fragmentos despliegan nos resultan muy contemporáneos — cultura libre, comunidad, feminismos, potencias de lo común y del anonimato-y, al tiempo, constituyen una crónica de la elaboración y adquisición concreta, cotidiana, puntual de esos saberes por medio charlas, clases, conversaciones, crianzas y lecturas. Son un hacer que muestra cómo se hizo.

El octavo y último de los ensayos que aquí interpelo es la obra más reciente de Santiago Alba Rico, Ser o no ser (un cuerpo) (2017), en mi subjetiva opinión, el pensador y crítico ibérico más interesante de las dos últimas décadas, capaz de analizar las transformaciones epistemológicas, antropológicas y culturales propias del neoliberalismo tardío con precisión, serenidad y dureza, gracias a un lenguaje exquisito, y un amor por la metáfora y por la sostenibilidad inmensos y equivalentes. Su forma de tomar el pensamiento desde la literatura y la literatura desde el pensamiento es singular y obedece a una vasta formación, que comienza desde y contra la academia filosófica (con Carlos F. Liria en Volver a pensar 1989) y que hoy se manifiesta desde un cuarto propio conectado en Túnez. La suya es una rica trayectoria como ensayista (Leer con niños, Capitalismo y nihilismo...), que, el 15M transformó en herramienta política, con fuerte impacto en el nuevo periodismo crítico y los entornos discursivos y asociativos del quincemayismo. 
En todo caso, Ser o no ser (un cuerpo) es una nueva vuelta de tuerca a los conceptos clave del filósofo en su denuncia contra las formas de vida neoliberales, que atentan contra lo que de común hay en la sociabilidad humana, en las condiciones materiales que permiten la reproducción de la vida colectiva y del medio que la sostiene. Así, Alba Rico reflexiona sobre los regímenes de mirada globalizados, propios del capitalismo avanzado, y su correlativa desposesión de lo humano, que comienza por la auto-desposesión del propio cuerpo. La disociación entre mirada, espacio y cuerpo estaría en la base del dilema antropológico que Alba Rico asedia: su reunión supone las condiciones sensibles mínimas que sería necesario proteger para garantizar la viabilidad de una antropología diferente, que resista a la máquina de muerte que es la distribución espectacularizada de la mirada en la sociedad global. Pero hay algo relativamente novedoso en este ensayo, frente a sus antecedes, que tiene que ver con su forma de producción, con el proceso que le subyace. Si el teatro, y su puesta en escena, ha tenido importancia en la trayectoria de Alba Rico (desde La Bola de Cristal hasta las dramaturgias que ha estrenado, como B-52), en el caso de Ser o no ser (un cuerpo), la configuración del libro se hace posible en relación con un laboratorio de «Teatralidades disidentes», amparado por el MNCARS y el Colegio de Móstoles, a lo largo de una serie de seminarios en los que Alba Rico iba circulando su texto a medida que lo elaboraba (hoy el texto se encuentra así disponible en pdf), lo que servía de punto de partida filosófico y conceptual para otros trabajos artísticos y educativos en los que participaban diversos artistas, educadores e infantes.

\section{Algunas hipótesis sobre la escritura ensayística aquí y ahora.}

Los ejemplos anteriores —o mi descripción de los mismos_ quizá puedan dar algunas pistas sobre ciertas direcciones hacia las cuales hoy parece expandirse la escritura ensayística en la península. No resultan espacialmente novedosas: se trata de prácticas que ya se vienen dando desde hace algunos años (a veces de la mano de unos mismos autores), y que quizá resulten relevantes precisamente en su reiteración. Su valor es puramente orientativo, pero lo creo igualmente relevante, pues su repetición nos orienta sobre modos de hacer que se estarían probando necesarios. Trataré de resumir las formas propias de esta zona de escrituras expandidas en una serie de rasgos — que cabe articular en seis puntos diferentes- en los que se concretan los modos de ser y de darse de dicha propiedad por medio de operaciones escritas. Veremos cómo dichas cuestiones se implican mutuamente. 
En primer lugar, cabe certificar la efervescencia de la prosa de ideas, el excelente momento del género — o de esta zona de escrituras — en el aquí y ahora digital-analógico de la edición peninsular. El volumen de ensayos que se publica es ingente y no tiene pinta de disminuir, y además proliferan nuevos tipos de criaturas. Estas prosas manifiestan gran diversidad de toda suerte: formal, estilística o conceptual. Su diversidad implica tanto a los sujetos que las elaboran como a quienes las transforman y conectan con otras zonas de mundo social. Y es que la crisis de 2008 ha representado una ruptura epistemológica para una gran cantidad de personas, tratando de construir relato y mundo a partir de la experiencia brutal de la misma. Las respuestas desde la escritura ensayística aquí son clave, porque se conectan no solo con una cultura libresca previamente existente, sino con nuevas instituciones culturales y tejidos asociativos surgidos de y por la crisis, de y por sus reacciones. Hay un nuevo mundo de revistas, editoriales, nuevos medios, redes de afinidad, etc. El empobrecimiento económico y el disciplinamiento social derivado de las políticas austericidas conlleva, al tiempo, una crisis de sentidos históricos, sobre la cual redes ciudadanas de toda índole tejen sentidos. Una intensa conversación social hoy permea ciertas zonas de escritura. Sólo desde esas materialidades asociativas cabe comprender los ensayos previamente analizados, desde su existencia material a la de sus lectores. O la de los conceptos que estos elaboran, sus contenidos y sus tonos.

En ese sentido, en lo que sería un segundo rasgo propio de este momento ensayístico, podemos hablar de una demanda informativa derivada de las frecuencias propias de un actual estado crítico. Las coordenadas políticas, sociales y económicas de la crisis son complejas y se manifiestan de muchas maneras, pero en las nuevas formas de ensayo de las que me he ocupado hasta aquí me parece distinguir algunos elementos comunes en el tipo de pensamiento que estas alimentan y por el que son sostenidas. De un lado, resulta notable cierto desplazamiento de preocupaciones específicamente nacionales a miradas que atienden a lo global, no como antítesis de lo español (como venía siendo habitual en mucho ensayo de las últimas décadas) sino como marco de conformación de lo peninsular. Incluso un libro como el de Martínez sobre la discursividad nacionalista es post-nacional en su forma de análisis, pues no asume la centralidad del modo estado-nación como ámbito de referencia de prácticas, lenguajes o valores.

La disolución (relativa) del binomio español vs internacional es fruto, de un lado, de la 
evidencia de la condición retórica de la soberanía nacional, propia de las formas de intervención económica sobre las competencias del estado vista en la crisis, pero también expresa otras facetas. De un lado, el desplazamiento geográfico — vital y mental— de muchas de las autoras de estos libros, con experiencia internacional, residentes en el extranjero, insertas en redes de discusión globalizadas. De otro lado, y más importantemente, una crisis más profunda de una forma de ser y de pensar propia de las últimas décadas: la llamada «cultura de estado» pierde su capacidad de devenir mundo. Y, así, se desequilibra y, con ella, el conjunto de saberes que tomaban por referente último el bienestar, necesidad y progreso de ese ente imaginario llamado «España» aun cuando tuviera como apellido «democrática». Las tomas de escritura de las que aquí me ocupo —en general— no creen en la existencia de esas criaturas llamadas naciones y, en su lugar, dedican su imaginación a concebir la existencia de comunidades ciudadanas, dando así por resultado imaginarios comunitaristas, cívicos y asociativos.

Se comparta o no, la existencia de un exitoso paradigma crítico que declara la crisis del Ilamado «régimen de 1978» es sólo una de las manifestaciones de este desplazamiento de lo nacional-estatal a lo demótico-civil. El independentismo catalán, según Martínez, sería una reacción contra-cíclica a ese mismo desplazamiento. En todo caso, las amenazas que la crisis del 2008 — y las lógicas culturales del neoliberalismo— suponen para las formas de vida de estas comunidades obliga a la producción de saberes alternativos útiles. Al tiempo, la quiebra de las formas culturales históricamente asociadas con el estado-nación dispara respuestas de toda suerte, que van desde el imaginario de la re-organización política de Yuste (desde una virtus incorrupta), hasta el capítulo final de Sergio del Molino, donde despliega una utopía glocal de lo campestre, basada en diálogos post-nacionales entre sensibilidades diversas resituadas - a un nivel planetario-en diferentes posiciones de lo rural recobrado, capaces de recuperar tradiciones y ecosistemas pero re-articulándolos globalmente. A su vez, Sanz recupera, en tiempos de crisis, frente a las formas políticas de dicho estado-nación, otra experiencia —recluida en lo privado, negada y pendiente de elaboración — de los tiempos de su fundación post-franquista, capaz de trabajar al servicio de una ética civil democrática.

Como tercer rasgo que pudiera permear algunas de estas escrituras ensayísticas, cabría también enfatizar la pluralidad —y quizá la ampliación — de las metodologías. Las formas más literarias propias del ensayismo se verían hoy reforzadas por nuevas prácticas de escritura 
y comunicación propias del periodismo digital, lo que conlleva desde otra sintaxis a otra bibliografía. También requiere asumir la intermedialidad como materialidad propia de la escritura, modos de recurrencia por hipervinculaciones. Y, en un nivel más comunicativo, implica modos de relación con el lector más horizontales, más conscientes de la precariedad de las lealtades digitales, frente a los llamados «públicos cautivos» de la (escritura de ensayo en la) prensa en papel. Un paso más allá, cabe hablar del influjo — por fin— fecundo de las formas académicas sobre la escritura ensayística: la propia precarización laboral del mundo universitario, en los últimos años, ha producido un trasvase sin precedentes de saberes académicos hacia la esfera pública digital. La cultura becaria y precaria de las universidades alimenta hoy toda suerte de espacios comunitarios, redes alternativas y/o trabajos liberados, especialmente desde los ámbitos humanísticos, pero no sólo.

En este mismo sentido, de transferencias metodológicas, creo que el hispanismo norteamericano está haciendo un trabajo de divulgación de saberes propios de los estudios culturales que, cada vez con más frecuencia, reconozco en textos ensayísticos peninsulares. Quepa mencionar que hoy el ámbito de lectura y circulación de ideas ya no es primeramente nacional. En este sentido, cabe citar dos ensayos recientes, donde las mediaciones de saberes académicos propios de la academia norteamericana hacia la esfera pública ibérica vía escritura ensayística son transparentes: de un lado el libro de Edurne Portela (El eco de los disparos 2016) a propósito del conflicto vasco, en el cuál la cultura, sus producciones y circulaciones sirven de herramienta analítica y deconstructiva de las guerras discursivas propias del contexto vasco, desde un radical compromiso con una ética de derechos humanos. En segundo lugar, me parece relevante el libro de Monserrat Galcerán, La bárbara Europa (2017), en la medida en que representa una puesta al día —vía Berkeley— de los saberes sobre post-colonialidad en el contexto de la crisis política europea y del recrudecimiento de las políticas extractivistas de la Unión Europea en el tercer mundo. Su publicación en Traficantes de Sueños asegura su camino de vuelta — vía cultura liberada— hacia los lectores latinoamericanos.

La confluencia de técnicas académicas y periodísticas, la combinación de investigación y divulgación y la internacionalización de los saberes son fenómenos derivados de una transformación profunda tanto del medio académico como de los profesionales de la información. A pesar de la diversificación de los perfiles profesionales en las plumas del ensayismo actual, 
se reconoce la precarización de sus vidas laborales, sobre todo entre las nuevas generaciones, en lo que me atrevo a pensar como un rasgo organizador de estas escrituras. El precariado de la universidad seiscientoseurista, los free-lancers de los medios sin nómina posible, los explotados disfrazados de autónomos, la diáspora académica configuran una nueva clase creativa e intelectual (aunque parte de la misma hallase temprano refugio en nuevas formas de institucionalidad política). Sus miembros hoy tienen mucho que contar $-y$ más que van a tener-y su propia (in)condición laboral los hace sensibles a las marchas y transformaciones de su tiempo, a través de las cuales conforman sus escrituras y buscan públicos y salarios. Muchas de sus firmas trabajan en la actualidad por liberar los saberes de los tiempos de producción y de las economías de subsistencia, por ensayar escrituras de lo común, y en lo común, basadas en otras formas de producir valor. En el ámbito ibérico, Remedios Zafra se ha hecho cargo profusamente de estas derivadas en su sentido macro. Si las relaciones estrechas entre cultura y estado propias del franquismo y de la monarquía constitucional comprometen bienes, salarios y habitus (en el sentido de Bourdieu), la precarización podría liberar la producción intelectual de vínculos inconscientes con el estado y sus necesidades ideológicas. Sobre las complejas derivadas de una Cultura libre de estado (2016) también — de nuevo desde Traficantes de Sueños— ha reflexionado recientemente Jaron Rowan, argumentando en favor de nuestro análisis. Es necesario subrayar que, además, una grandísima parte de estas nuevas agentes culturales precarizadas son mujeres, por lo que los efectos y reacciones a esta precarización conllevan y van a conllevar cada vez más una toma de escritura feminista.

Un quinto rasgo que atraviesa estas escrituras tiene que ver con los múltiples efectos derivados de la ampliación estructural de la esfera pública sucedida en los últimos años, algo de lo que ya me he hecho cargo, pero que conviene marcar específicamente. Con toda la pluralidad que fuese capaz de integrar, el modelo cultural hegemónico de las últimas décadas sigue dándose. A través del mismo se manifestaba la literatura ensayística. Hoy, las editoriales y medios que lo sostenían siguen dándose, pero - y esta es la novedad- su lenguaje ya no responde (o no decisivamente) a la experiencia de una gran parte del público lector y escritor. En particular, esta cultura no interpela a las cohortes más jóvenes de la sociedad adulta. Como era de esperar, hoy las editoriales (también las de ensayo) son otras, otros son los medios donde publican hoy las autoras (también las ensayistas) y otros son los circuitos donde las escrituras impactan y se discuten, se hacen mundo. 
Esas formas de discusión y producción han desdibujado las barreras tradicionales basadas en el anonimato entre autor y lector, y, con ellas, la autopercepción aislada propia de los mundos intelectuales y académicos. La noción de espacio público se ha hecho más densa, más multiforme, más trabada. Y hay escrituras que se hacen más cargo que otras de las nuevas formas de discusión y escucha propias de los nuevos estadios (polifonía, intermedialidad, antirretoricismo, etc). Al tiempo, por efecto de la crisis y de sus reacciones, estas nuevas zonas expandidas de la esfera pública, y el nuevo campo cultural que se asocia con las mismas, con sus agentes, se ha politizado de forma increíble en los últimos seis años, por lo que sus tomas de palabra se atraviesan y vertebran desde lo político, como pasión y como lenguaje, como modo de la sensibilidad y como permanente pregunta por las condiciones de comunicación y escucha. Este nuevo entorno es más rico en su masa crítica y, al tiempo, más exigente. Debido a la propia naturaleza de los medios digitales que sostienen su ampliación, este medio también es más horizontal, lo que ha producido una democratización de las tomas de palabra y un profundo, estructural desajuste en los modos de producción de valor en su interior. Este se traduce en verdaderas rupturas comunicativas de un lado a otro del umbral digital, entre las escrituras anfibias y las visceralmente analógicas.

De una u otra forma, el sexto de los rasgos ya ha sido profusamente aludido: se trata de la revolución digital, de sus efectos en los modos de circular, recibir y producir lenguaje, de su impacto en el ámbito de la escritura y la cultura. Las escrituras ensayísticas actuales son digitales pero no porque las leamos en un blog o descarguemos en ebooks sino, en primer lugar, porque su forma de producción depende de una cultura digital. Hoy los accesos a la información y a los repositorios son digitales, y la investigación es en red, mientras que la extensión de conocimientos a la que la escritura nos convoca sólo pueden ser adquiridos desde poderosos motores de búsqueda, sean hemerotecas o Wikipedia, googlebooks o catálogos digitales. Si esto puede resultar evidente, quizá no lo sea tanto que haya formas de edición y de escritura expandidas — varias de las que hemos tratado— accesibles por sistemas de copyleft y pre-prints, de acceso libre global o de plataformas de micro-mecenazgo. Pienso en libros que he ayudado a hacer posibles, como es el caso de la monografía de Jorge Linheira sobre las políticas culturales en la Galicia post-2008 o la recopilación de ruinas de la crisis del ensayo visual de Nación Rotonda. 
Así, el lugar de los lectores y de los editores se ha comenzado a confundir también en los ensayos. A veces también el del autor-editor-periodista-promotor, como demuestra la producción del aterrador ensayo de Natharet Castro sobre los efectos del neoliberalismo en la alimentación (La dictadura de los supermercados, 2017), que condensa la experiencia y saberes adquiridos tras de una trayectoria como periodista, migrante y bloguera, junto con su colaboración con Laura Villadiego en el proyecto colectivo de periodismo independiente Carro de Combate. Consumir es un acto político, basado en la micro-financiación y dirigido a facilitar información fiable sobre las prácticas nihilistas de los mercados de alimentación globales, desde circulaciones informativas no verticales.

Hay otros libros de los que me habría gustado ocuparme aquí, como el de Carolina León o el de Silvia Nanclares, aparecidos estos meses, pero se me han quedado encima de la mesa, apenas ojeados, sin el tiempo de leerlos. Me habría gustado asociarlos a hipótesis como las presentadas, a pesar de que, espero, a estas alturas los argumentos generales han quedado claros. Las formas de ensayo de las que aquí me he ocupado representan, en su concepción y su circulación, otras tantas mutaciones estructurales de la cultura en este rincón planetario llamado España. Nos hablan de formas de escribir diversas y dinámicas, habitadas de una urgencia por explorar el presente y responder a sus desastres, las propias de una ciudadanía que se quiere global, post-nacional y feminista, que trata de dar respuesta a las demandas de sentido propias de la crisis, y a las brechas que esas demandas han abierto en los sentidos de otros periodos y fenómenos históricos, hasta cuestionar el metarrelato de la larga marcha del subdesarrollo a la normalidad democrática, por vía de mostrar sus zonas grises, sus silencios, sus borrados.

Con un pie en las nuevas formas de periodismo y sus demandas de comunicación y un ojo en los saberes académicos — y en especial en sus recursos teóricos- las nuevas autoras de ensayo imaginan diálogos expandidos y democratizados con públicos más presentes cuanto más difusos, más extensos cuanta más capacidad de manifestarse adquieren por canales digitales, aunque mientras tanto no sepan de qué van a vivir en el futuro o cómo pagar el alquiler o el implante dental. Pero su condición precaria, al tiempo que las hace más conscientes de las determinaciones del presente o las obliga a reaccionar a las mismas, también las libera de otras servidumbres ideológicas propias de las formas de mecenazgo público estatal-institucionales. La profunda mutación de la esfera pública sucedida en los últimos años a lomos de las revoluciones 
digitales y las prácticas de cultura libre que, en ocasiones, estas amparan ofrece una audiencia formidable a múltiples voces emergentes y obliga y permite trabajar la escritura y sus ensayos de otros modos. En resumen: habrá, seguro, otros libros que hagan otras cosas, pero los que he seleccionado hacen estas. Creo que, por estos haceres (haceres que permiten decires), nos interesan a muchas personas hoy: no estoy sólo en mis gustos por obras que ni crean ni destruyen el pensamiento, sino que lo transforman esperando transformar el mundo (su mundo) en tal proceso. Este consistiría en el único modo de no resignarse a su destrucción en el aquí y ahora, un ensayo de su mantenimiento, de su posibilidad de expandir su vida común.

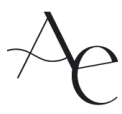

\section{Bibliografía}

15MP2P. Encuentro transdisciplinar del 15M. 2014. Barcelona: IN3/UOC. Web.

Acemoglu, D. y J. A. Robinson. 2013. ¿Por qué fracasan los países? Bilbo: Deusto Ediciones.

Alba Rico, S. y C. F. LIRIA. 1989.Volver a pensar. Una propuesta socrática a los intelectuales españoles. Madrid: Akal.

AlBA Rıco, S. 2007. Leer con niños. Madrid: Akal.

---------2007. Capitalismo y nihilismo Madrid: Akal.

---------2017. Ser o no ser (un cuerpo). Barcelona: Seix Barral.

Amat, J. 2016. Primavera de Munich. Esperanza y fracaso de una transición democrática. Barcelona: Tusquets.

BUtLeR, J. 1990. Gender Trouble. Feminism and the Subversion of Indentity. NY: Routledge.

CASTRO, N. 2017. La dictadura de los supermercados. Madrid: Akal.

Del Molino, S. 2016. La España vacía. Madrid: Turner.

Estornés, I. 2017. Cuando Marx visitó Loyola. Donosti: Erein.

Galcelán, M. 2017. La bárbara Europa. Madrid: Traficantes de Sueños.

Garcés, M. 2016. Fuera de Clase. Barcelona: Galaxia Gutenberg.

Gracia, J. 2011. El intelectual melancólico. Barcelona: Anagrama.

IZQUIERDO, J. 2014. «Reabrir el oscuro objeto del deseo de la transición. Un enfoque poscolonial». 
En: Democracia Inocua. François Godicheau y Pablo Sáchez León (ed.). Madrid: Ediciones Contratiempo, pp. 21-39. Web.

Labrador Méndez, G. 2016. «New Directions in Iberian Cultural Studies? (Gloto)political Geographies of Peninsular Hispanism After 2008». In: The Place of Hispanic Linguistics and Literary/Cultural Studies, Hispanic Issues On Line Debates, 6, pp. 50-71.

2017. Culpables por la literatura. Imaginación política y contracultura en la transición española (1968-1984). Madrid. Akal.

LEÓN, C. 2017. Trincheras permanentes. Intersecciones entre política y cuidados. Logroño: Pepitas de Calabaza.

LÓPEZ, E. y RodríGuez. 2010. Fin de ciclo: financiarización, territorio y sociedad de propietarios en la onda larga del capitalismo hispano (1959-2010). Madrid: Traficantes de Sueños.

Martín Gaite, C. 1978. El cuarto de atrás. Barcelona: Destino.

Martínez, G. 2012. CT o la Cultura de la Transición. Barcelona: Debolsillo. 2016. La Gran Ilusión. Mito y realidad del proceso indepe. Barcelona: Debate.

Moreno, L. 2017. Culturas de cualquiera. Madrid: Antonio Machado/Acuarela libros.

NANCLARES, S. 2017. Quién quiere ser madre. Madrid: Alfaguara.

NAZARIO, L. V. 2016. Vida cotidiana del dibujante underground. Barcelona: Anagrama.

Portela, E. 2016. El eco de los disparos. Barcelona: Galaxia Gutenberg.

Rodríguez, E. 2016. La política en el ocaso de la clase media. Madrid: Traficantes de Sueños.

Rowan, J. 2016. Cultura libre de estado. Madrid: Traficantes de Sueños.

SÁnchez Cuenca, I. 2016. La desfachatez intelectual. Madrid: La Catarata.

Sánchez-Mateos Paniagua, R. 2016. «Nuestra herencia en encanto y dulzura». Sierra de Guadarrama: Talares de la Manga. (No he encontrado ninguna referencia a este texto en Internet, como para desambiguar si se trata de un artículo (comillas) o libro (cursiva) (es un opúsculo de una editora underground, un artículo por extensión, pero publicado de forma exenta, como un librito)

SAnz, M. 2013. Daniela Astor y la caja negra. Barcelona: Anagrama.

-2016. Éramos mujeres jóvenes. Una educación sentimental de la transición española. Barcelona: Planeta.

VÁzquez Montalbán, M. 1970. Crónica sentimental de España. Barcelona: Lumen.

YUSTE, R. 2017. Ibex 35. Una historia herética del poder en España. Madrid: Capitán Swing. 